\title{
Laser induced phagocytosis in the pigment epithelium of the Hunter dystrophic rat
}

\author{
P. L. ANSELL AND JOHN MARSHALL \\ From the Department of Visual Science, Institute of Ophthalmology, London
}

The membrane systems in the outer segments of rod photoreceptor cells in the retinae of normal rats are in a state of flux. The bimembranous discs of which the outer segment is composed (Pedler and Tilly, 1967) are continuously being renewed throughout life (Young, 1967). New discs are formed in the region of the inner segments of the receptor cell and are progressively displaced towards the pigment epithelium by successive disc production. The time taken for a newly-formed rat disc to traverse the outer segment is about nine days (LaVail, Sidman, and O'Neil, 1972). Old discs at the tips of rod outer segments are removed by the phagocytic action of the pigment epithelium (Young and Bok, 1969). The spent discs are engulfed by the epithelial cell in groups of varying numbers, but at a rate which approximately equals the rate of production. Thus in adult animals no marked change in receptor length is recorded. Once inside the pigment epithelium the groups of discs, called phagosomes, undergo lysis which results in their progressive degeneration (Marshall, 1970a; Ishikawa and Yamada, 1970; Marshall and Ansell, 1971).

Morphological studies on the retinae of rats with retinitis pigmentosa have shown the presence, and progressive accumulation, of membranous material between the outer segments of the retinal receptor cells and the pigment epithelium (Dowling and Sidman, 1962). This extracellular material has been shown to originate from the spent discs of receptor cells (LaVail and others, 1972). It has also been demonstrated experimentally that the accumulation of receptor debris is not related to an increased rate of production of rod discs (Herron, Riegel, Myers, and Rubin, 1969), but to the absence of uptake of this material into the retinal pigment epithelial cells (Bok and Hall, 1971). These findings have led to the conclusion that in rats with retinitis pigmentosa a malfunction exists in the phagocytic relationship between the receptor cells and the retinal pigment epithelium. Such a breakdown could arise from anomalies inherent in either the receptor cell or in the pigment epithelium. Several workers have demonstrated that the pigment epithelium of these animals contains the lytic enzymes capable of inducing phagosome degradation (Burden, Yates, Reading, Bitensky, and Chayen, 1971; Ansell and Marshall, 1974). Thus either the spent rod discs are altered in some way and hence the pigment epithelium will not engulf them, or the apical membrane of the pigment epithelium is at fault and will not allow the spent discs to pass through. Some biochemical anomalies have been found in the outer segments of these animals; for example, Schmidt and Lolley (1973) and more recently Dewar, Barron, and Richmond (1975) showed that the retinae of mice and rats with retinal dystrophies are deficient in the enzyme, retinal phosphodiesterase. It has been suggested that the resultant accumulation of cyclic nucleotides-such as, adenosine $3^{\prime}, 5^{\prime}$ monophosphate and guanosine $3^{\prime}, 5^{\prime}$ monophosphate-could result in the changes associated with the anomalous photoreceptor differentiation and function (Farber and Lolley, 1974; Dewar, Barron, and Reading, 1975), although further work on the Royal College of Surgeons (RCS) rat suggests that these changes are secondary and related to the accumulation of photoreceptor debris (Lolley and Farber, 1976). There is now increasing evidence that the phagocytic process of the pigment epithelium is discriminatory (Hollyfield and Ward, I974a, b). Thus in dystrophic animals the lack of phagocytosis may be caused by the receptors presenting the wrong signal to the apical membrane of the pigment epithelium. Corroborative evidence for this hypothesis has been obtained recently in two separate experimental investigations (ReichD'Almeida and Hockley, 1975; Custer and Bok, 1975). Both these groups of workers injected substrate material into the subretinal space of dystrophic rats, the former used carbon particles while the latter employed photoreceptor outer segment fragments isolated from normal rats. In both series of experiments the substrate particles were engulfed by the pigment epithelium of the dystrophic animals and appeared as membrane-bound inclusions. The 
phagosomes of outer segment material described by Custer and Bok (1975) were identical with those found in normal animals.

In normal animals if the retina is experimentally damaged either by laser irradiation (Marshall, I970a; Marshall and Mellerio, 1970) or by ischaemia (Johnson, 1975) the endemic phagocytic activity of the pigment epithelium becomes hyperactive and clears the debris from the damaged site. In contrast with ischaemia, lasers produce a controlled localized area of damage. At the centre of the irradiated area many pigment epithelial cells and their associated receptor outer segments experience a great increase in temperature and therefore become thermally denatured (Marshall, I970b). However, in the peripheral zone of the lesion the epithelial cells recover from any transient thermal insult and begin to form new cells, many of which dissociate from Bruch's membrane and assume the activity of wandering macrophages (Marshall and Mellerio, 1970).

The current paper reports the induction of phagocytosis in the pigment epithelium of retinitis pigmentosa rats by exposing them to low-power laser irradiation of the retina. It is not a therapeutic proposal.

\section{Methods and materials}

To ensure that laser energy was absorbed in the region of the pigment epithelium, pigmented dystrophic animals (Hunter strain) were used throughout this study.

To achieve maximum mydriasis 2 drops of $\mathrm{I}$ per cent cyclopentolate were instilled into one eye of each 14day-old rat. After 20 minutes the animals were anaesthetized with diethyl ether and then the eye was exposed to an experimental pulsed ruby laser system mounted on a Zeiss slit-lamp (Perkins and Brown, 1973). The system used a $5.1 \mathrm{~cm} \times 6.4 \mathrm{~mm}\left(2 \times \frac{1}{4}\right.$ in) ruby rod which was air cooled and had a pulse duration of $450 \mu \mathrm{s}$. The laser beam passed through auxilliary optics and and was brought to a focus coaxially with the illumination beam of the slit lamp. The output energy of the laser was adjusted to between 5 and $30 \mathrm{~mJ}$ by introducing glass neutral density filters into the beam path. Beam power levels were monitored on a model 42 calorimeter (Laser Associates Lt 1 ) and displayed on a model 155 voltmeter (Keithley Instruments).

To locate lesions in specific positions on the rat's fundus, the refractory system of the rat's eye was negated by pressing a cover slip on its cornea. Three lesions were produced in one eye of each animal, and in each case these were located away from the optic disc or major vessels.

The animals were killed with chloroform on the fifteenth postoperative day, and their eyes were immediately removed. After a corneal incision each eve was immersed in $15 \mathrm{ml}$ of 2.5 glutaraldehyde buffered to $\mathrm{pH} 7.4$ in $0.1 \mathrm{~mol} / 1$ sodium cacodylate containing $10 \mathrm{mg}$ $\mathrm{ml}$ calcium chloride. Five minutes after immersion in this fixative a circumferential incision was made just posterior to the sulcus sclerae, and the anterior part of the eye, together with the lens and vitreous, were discarded. After a total fixation time of 20 minutes the lesions together with unirradiated control areas were isolated from the posterior eye cups using a dissecting microscope. Samples were then processed for light and electron microscopy or electron histochemistry as previously described (Ansell and Marshall, 1974).

\section{Results}

The morphology and acid phosphatase distribution in control areas of dystrophic retina were similar to those previously described (Ansell and Marshall, 1974), but in addition in the present series of experiments lead phosphate deposit indicating acid phosphatase activity was found over lysosomes within the pigment epithelium (Fig. I $a$ ).

In light microscopical examination of the pigment epithelium the irradiated areas could clearly be distinguished. The cytological appearance varied both with the irradiance of the initial exposure and with the distance of individual cells from the centre of the irradiated area.

In the higher energy exposures (10 to $30 \mathrm{~mJ}$ ) Bruch's membrane was deformed, multilayered, and enlarged in thickness, and often contained globular lipid-like inclusions.

In all exposures the entire area of the lesion was covered by pigment epithelial cells (Fig. $\mathrm{I} b$ ). These proliferated epithelial cells were either flattened and elongated (size $20 \times 5 \mu \mathrm{m}$ ) or rounded and globular (size $15 \mu \mathrm{m}$ ). The flattened cells were spindleshaped and maintained contact with Bruch's membrane over a large part of their basal surface area (Fig. 2a). In contrast, the globular cells projected into the outer segment region of the photoreceptor cells and were either separated from Bruch's membrane, or associated over a limited area of their circumference sometimes only by villiform projections (Fig. $2 b$ ). In the periphery of many lesions, rounded pigmented cells could be seen between normal pigment epithelial cells attached to Bruch's membrane, and the outer segments of photoreceptor cells (Fig. 2c). In other lesions within the central area a hyperplasia of the epithelial cells was observed, and consisted of successive layers of spindle-shaped poorly pigmented cells.

In low-energy exposures ( 5 to Io $\mathrm{mJ}$ ) the epithelial cells within the irradiated areas were irregular and either larger or smaller than those in control sections. Few cells were seen isolated from Bruch's membrane.

In all lesions the layer of subretinal photoreceptor debris normally found in these animals was either reduced or removed (Figs $\mathrm{I} b, 2$ ).

In both mild and severe lesions the various types of epithelial cells were seen to contain densely 

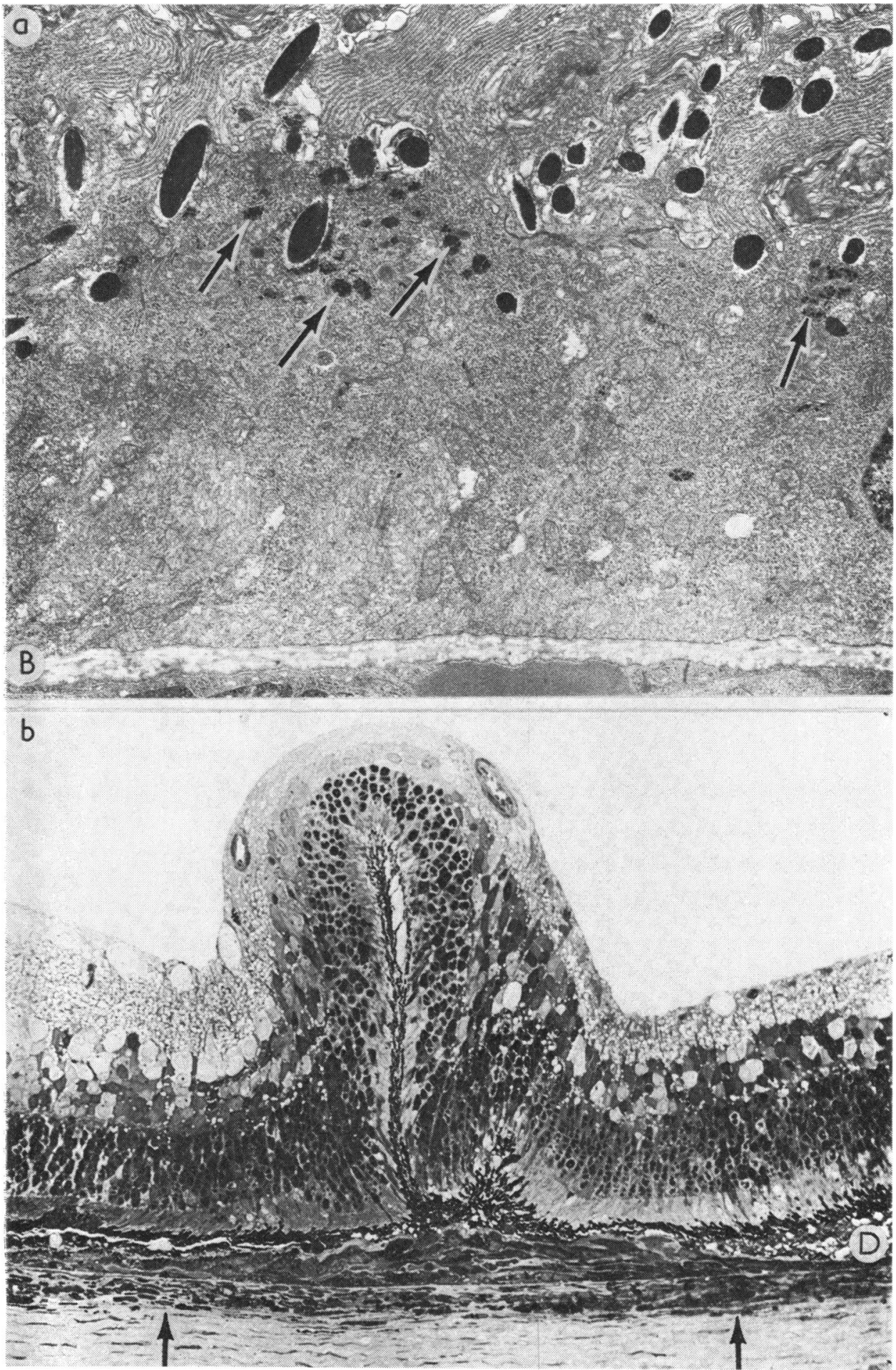

FIG. I (a) Electron micrograph of dystrophic rat pigment epithelium with lead phosphate deposits over lysosomes (arrowed), indicating presence of acid phosphatase: Bruch's membrane $(B) . \times 8400$

FIG. I (b) Light micrograph of centre of a 15-day-old laser-induced lesion in retina of a dystrophic rat. Regenerated pigment epithelial cells are present throughout irradiated area (arrowed), and are associated with a reduction of debris $(D)$ in the subretinal space. $\times 560$ 


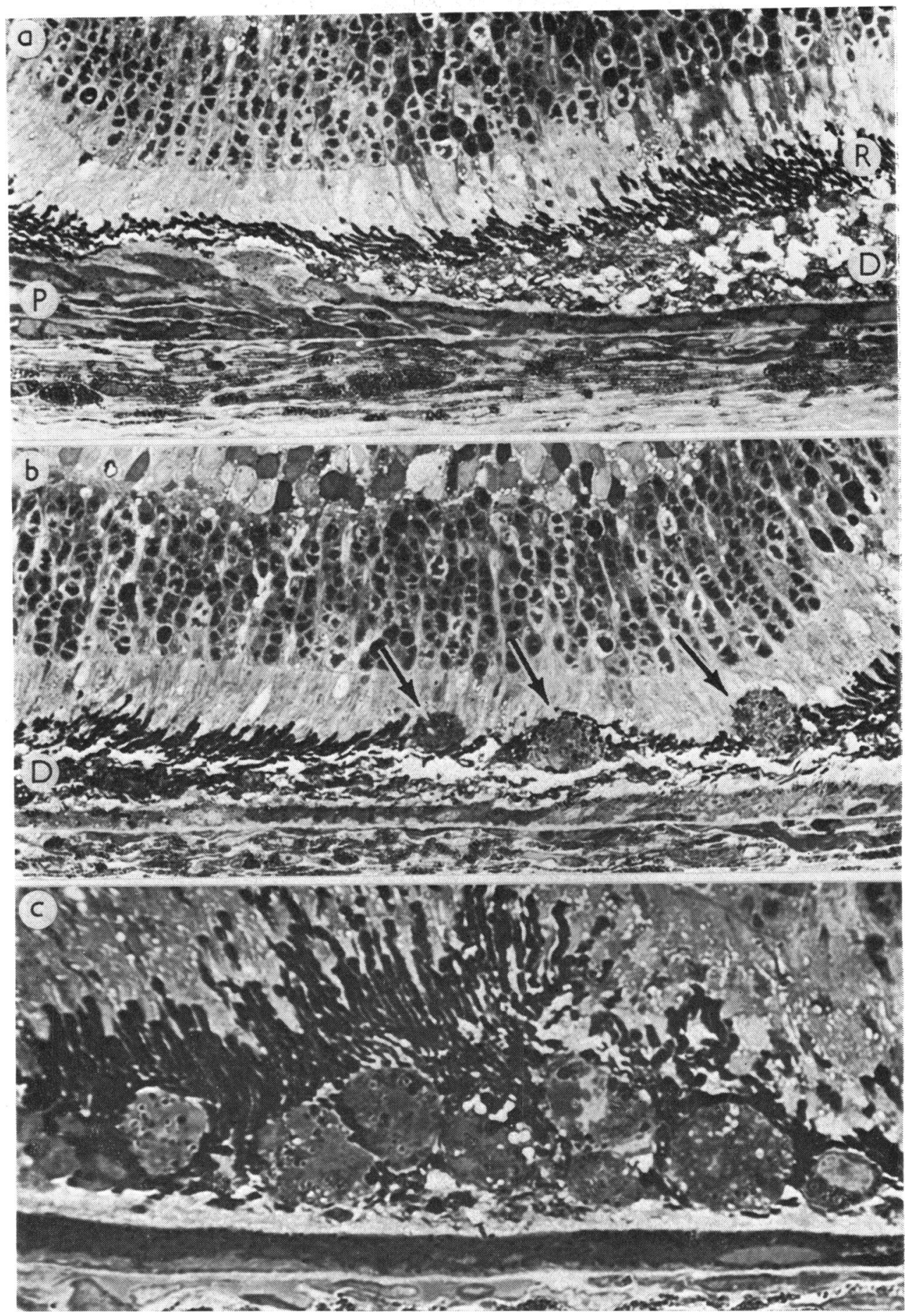

FIG. 2 Light micrographs of receptor epithelial junction in areas of dystrophic rat retina irradiated with laser light. (a) The subretinal debris (D) is lost over the multi-layered proliferated epithelial cells $(P)$. Photoreceptor cell outer segments $(R)$ are present throughout irradiated area. $\times 560$. (b) Globular regenerated epithelial cells (arrowed) in a subretinal space at edge of a laser lesion. $\times 560$.

(c) Proliferated epithelial cells containing phagosomes, at centre of a small laser lesion. $\times 1240$ 


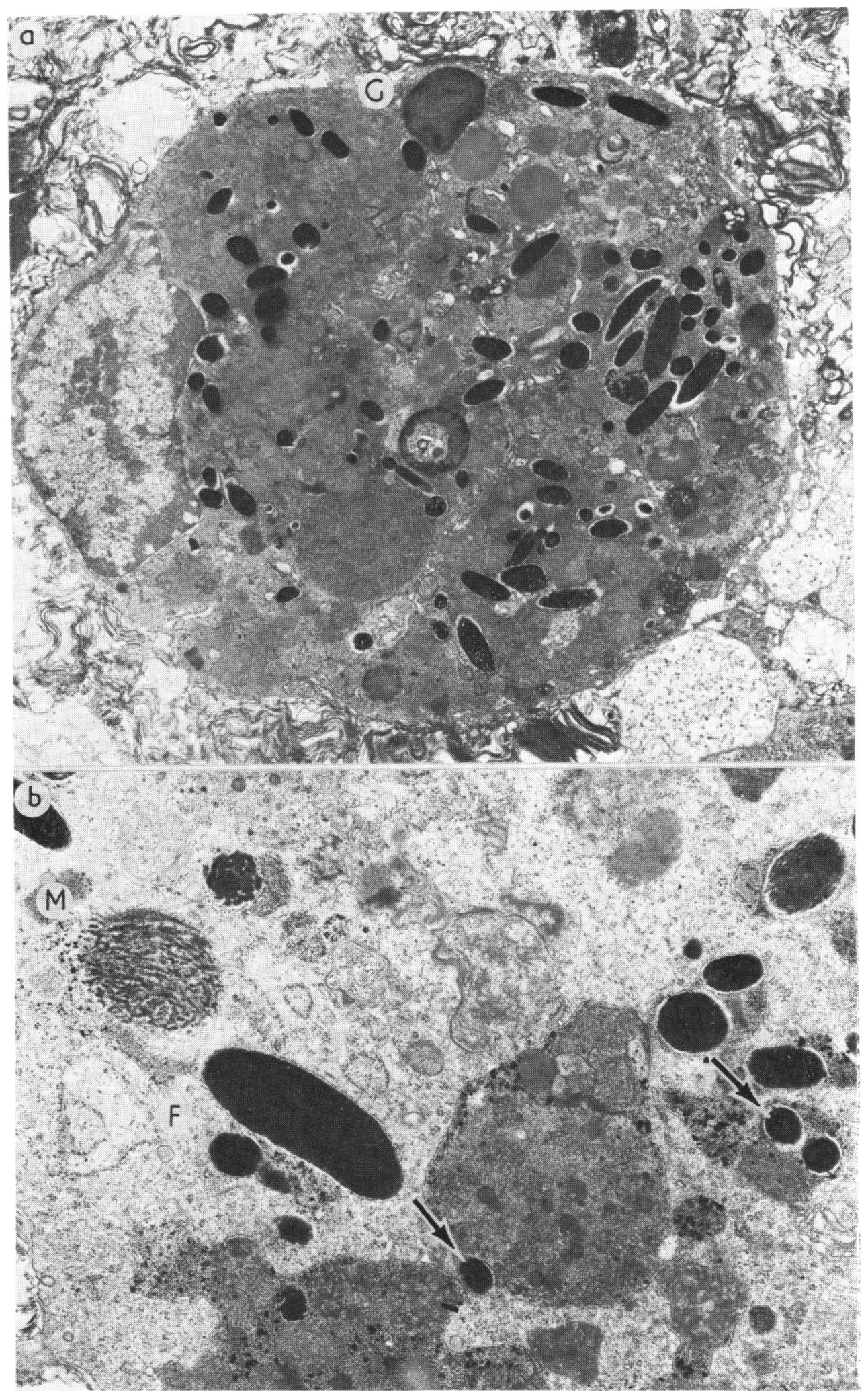

FIG. 3 (a) Electron micrograph of regenerated epithelial cell in the subretinal space. Cell contains phagosomes $(G)$ and both free and engulfed melanin granules. $\times 8000$. (b) Electron micrograph of organelles and inclusions in a regenerated epithelial cell : free melanin granules $(F)$ and premelanosome $(M)$, ingested melanin granules (arrowed).$\times 20000$ 
staining inclusions with the size and appearance of phagosomes.

On examination of the irradiated areas in the electron microscope the proliferated pigment epithelial cells had a substructure similar to that of normal retinal epithelial cells. They were seen to contain numerous organelles, including many associated with the normal development of pigment granules-for example, premelanosomes and mature melanin granules (Fig. 3). In some cells similar organelles were also found in groups or together with amorphous material within membrane-bound systems. In histochemical samples these membranebound inclusions were always associated with dense lead phosphate precipitates. Many cells contained engulfed particles of photoreceptor outer segments and these were similar to but larger than those found in the pigment epithelium of normal rats (Figs 3,4 ). The rounded cells that had separated from Bruch's membrane usually contained greater numbers of phagosomes per cell than the spindleshaped variety. In some few cases the active incursions of the bounding membrane of epithelial cells into receptor cell debris were observed.

In the samples taken from areas of irradiated retina tested for acid phosphatase activity, lead phosphate deposits were seen over the phagosomes and presumptive lysosomes (Figs $4 b, \mathrm{c}$ ). The intensity of the reaction varied with both the appearance and position of the phagosome. Peripheral inclusions with relatively unaltered membrane structure always had less lead deposit than the more central and disorganized structures. In contrast with the unirradiated areas little reaction product was seen associated with either the bounding membranes or the extra cellular debris.

In the areas of the lesion some receptor cells were destroyed and degenerating remnants of the inner portions of these cells were identified by their electron-dense staining. Occasionally photoreceptor cells in the periphery of the irradiated area were seen to contain phagosome-like material within their inner segments (Fig. 5).

\section{Discussion}

The pigmented cells observed in the irradiated areas of dystrophic rat retinae are similar to the proliferated epithelial cells described in other animals exposed to similar sources of radiation. In most animals the epithelial cells adjacent to the damaged area flatten and then extend along Bruch's membrane and into the lesion. These amoeboid processes coupled with new cells derived from either budding (Marshall and Mellerio, 1970) or mitotic division (Gloor, 1969) result in a re-epithelialization. In many instances the newly formed cells bud off from Bruch's membrane when they reach the centre of the lesion (Marshall, Frankhauser, Lotmar, and Roulier, 1971). The resultant wandering cells always contain large numbers of phagosomes (Fig. 3). In a study of phagocytic activity of the pigment epithelium of the frog (Rana pipiens) using pasteurized bacteria, large phagocytic cells were observed within the subretinal space, but the authors concluded that these were probably bloodborne leucocytes (Hollyfield and Ward, 1974a). This deduction was based on observations of differences in subcellular morphology and the fact that melanosomes were absent. Similar observations were used to discriminate between two populations of cells in studies on the salamander (Keefe, 1973), and on the rabbit (Marshall and others, I97I). Both these studies concluded that most of the wandering cells within the subretinal space were derived from the pigment epithelium, while a small number may be derived from the blood. In the current study most cells in the subretinal space contained normal premelanosomes and pigment granules and had an endoplasmic reticulum identical with that of pigment epithelial cells in unirradiated areas. We conclude, therefore, that most phagocytic cells within the irradiated areas of dystrophic rat retinae are of epithelial origin.

Several papers confirm the presence of a discriminating recognition process in the phagocytic mechanism of the pigment epithelium (Hollyfield and Ward, 1974a; Reich-d'Almedia and Hockley, 1975; Custer and Bok, 1975; Hollyfield, 1976). These workers showed that the pigment epithelium will ingest carbon particles and latex spheres, will not ingest pasteurized bacteria, and has difficulty in engulfing normal receptor outer segments prepared by subcellular fractionation. Clearly the pigment epithelium is relatively omnivorous for abiotic particles, but must possess a fine sensory mechanism to discriminate between a normal spent section of rod outer segment and one that has been subjected to in vitro isolation techniques.

The omnivorous response to inert particles suggests that the process of ingestion may not require a specific chemical induction system to activate the apical membranes of the pigment epithelium, as it is unlikely that carbon particles or latex spheres possess such systems. It has been stated that the surface charge of these particles may be important in the recognition process (Karnovsky and Wallach, 1963) as the charge on latex spheres is the same but of twice the magnitude as that of biological membranes (Feeney and Mixon, 1976). However, amorphous carbon particles have no net charge and are still readily engulfed. These observations imply that the membrane receptor sites of the pigment epithelium are non-specific, but that they possess an active rejection system when confronted with potentially harmful material. 


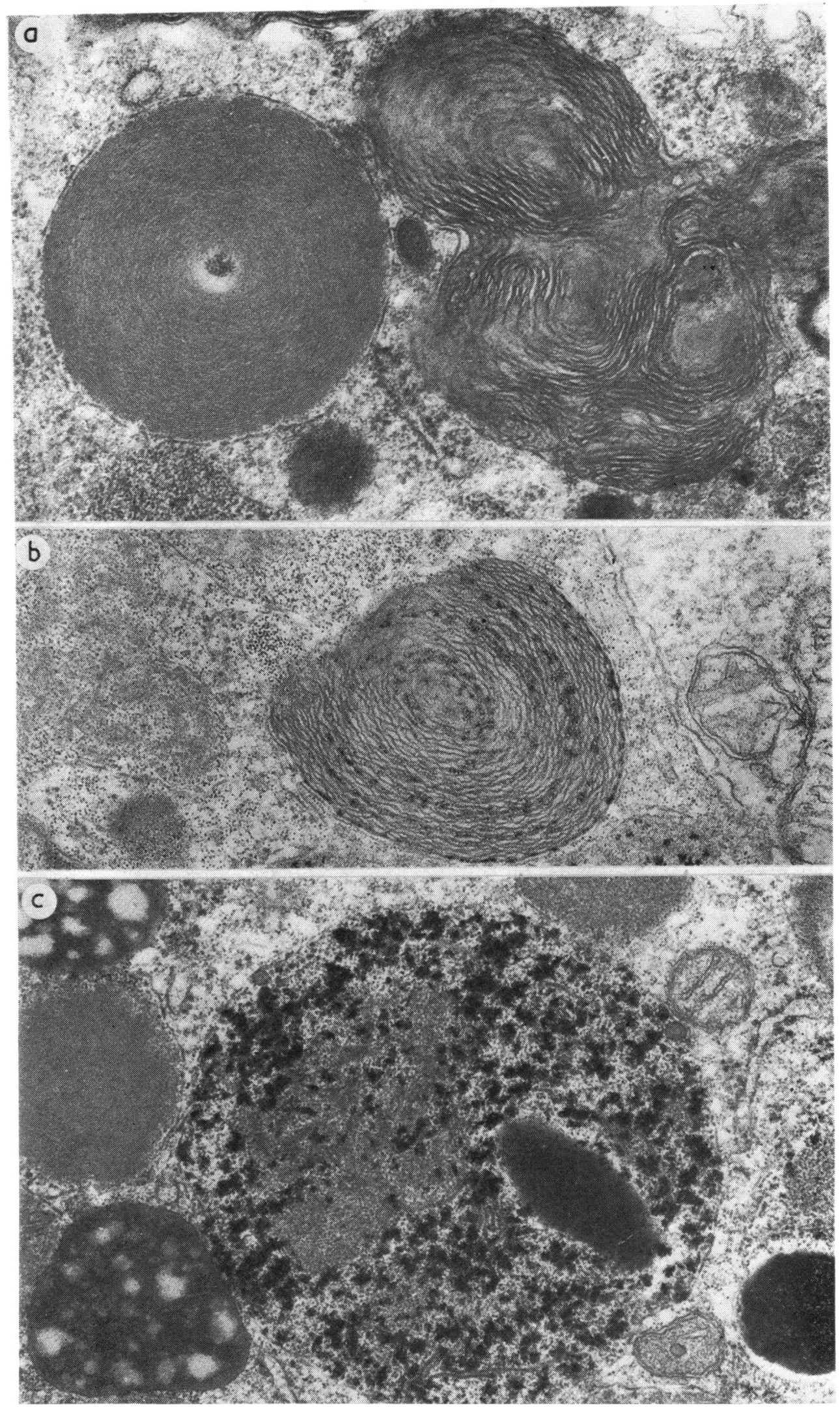

FIG. 4 Electron micrograph of inclusions in regenerated pigment epithelial cells of dystrophic rat. $\times 50000$. (a) Phagosomes within a pigment epithelial cell in the laser irradiated area. (b) A phagosome associated with lead phosphate deposits indicating acid phosphatase activity. (c) $A$ dense lead phosphate deposit associated with a phagocytic inclusion containing both amorphous debris and a melanin granu!? 


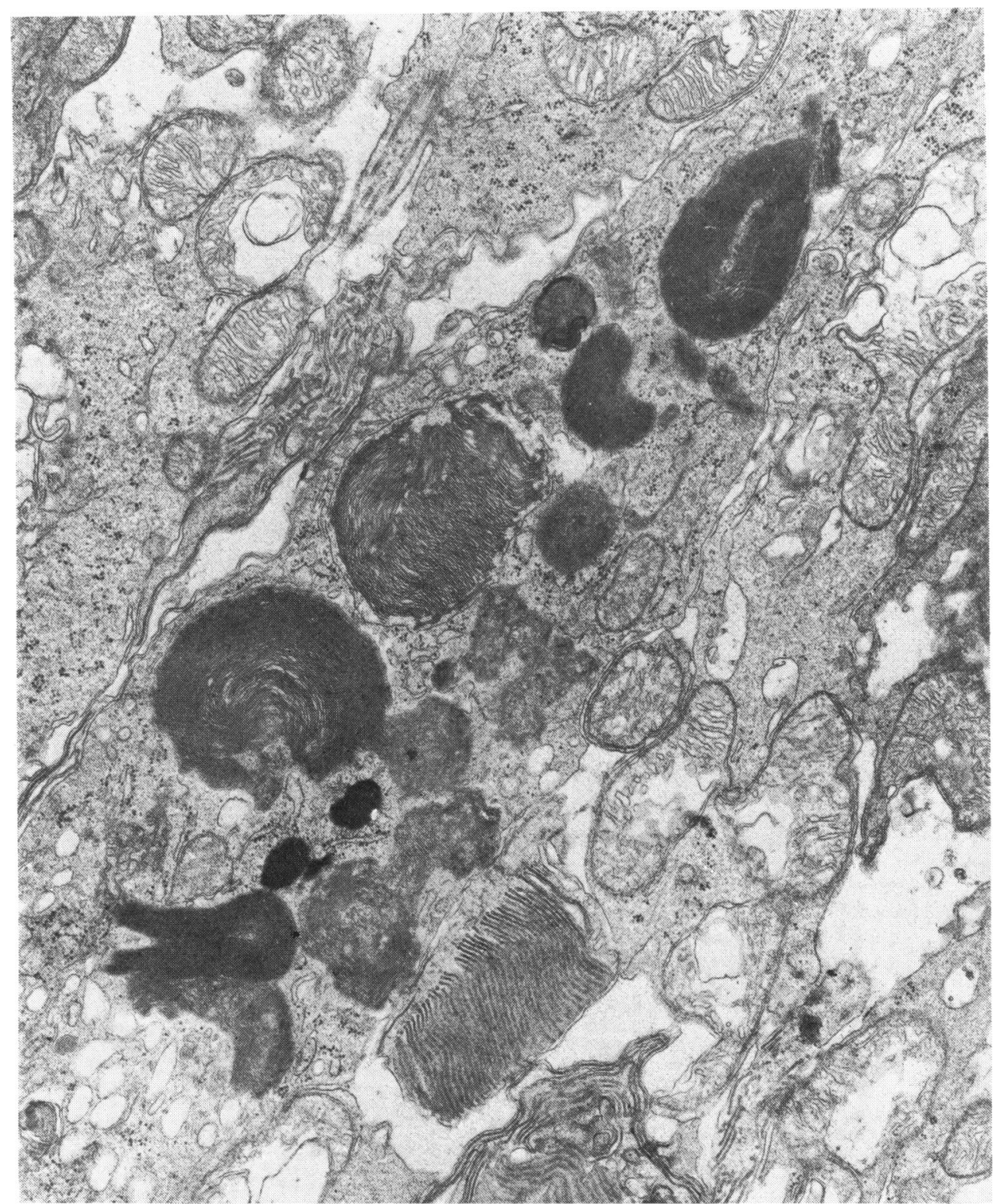

FIG. 5 Inclusions of photoreceptor outer segment material in inner segment of a cell in the periphery of a laser-irradiated area. Such inclusions have been termed autosomes. $\times 20000$

In the current study the debris from both damaged photoreceptor and pigment epithelial cells was ingested and shown to be in association with lytic enzymes. Pigment granules and premelanosomes are readily recognized as morphological entities within the boundary membranes of phagocytic particles. However, the appearance of membranous 'whirls' and their exclusive identification as phagosomes of outer segment material is difficult as such structures are characteristic of degenerating or damaged cells and have been observed in many systems (Meban, 1972; Tripathi and Ast.ton, 1976). In some instances the morphology of the phagosomes observed in the present study was such that their photoreceptor origins could be detern.ined. The lipid-like deposits within Bruch's membrane suggest that there is some resistance to voiding the breakdown products of lysis and that there may be an imbalance in blood retinal exchange. However, this probably 
arises because of the thickening of Bruch's membrane and the loss of choroidal capillaries within the irradiated area in severe exposures.

The observation of phagosomal particles within the inner segment region of some photoreceptors in the periphery of the irradiated area may relate to the recent findings of Reme and Young (1976). These authors describe such particles called autosomes in the cones of the ground squirrel during the loss of these receptors before hibernation. Observations in our laboratory show autosomal inclusions in cones to be characteristic of degenerative changes associated with both traumatic insult and ageing. The sparse distribution of cells with such inclusions in the present study could reflect a cone-like receptor population in rats (Leuredu Pree, I971).

Clearly the changes induced in photoreceptor and pigment epithelial cells as a result of laser irradiation removes the influence that precludes phagocytosis in the Hunter rat.

The proliferated epithelial cells must have the same genetic complex as their parent cells and therefore it would be difficult to consider them having significantly different biochemistry. In contrast the receptor cell outer segments within the irradiated area have been thermally denatured.

There are four primary mechanisms by which the morphological manifestations observed in dystrophic rats could arise (Custer and Bok, 1975).

I. The pigment epithelium lacks some component necessary for phagocytosis.

2. The rod outer segment either lacks an essential inducing agent, or possesses an inhibiting agent that precludes phagocytosis.

3. Both the above mechanisms are present in some combination and collectively contribute.

4. Complementary defects are present in the rod outer segment and the pigment epithelium and the disease manifestations are expressed only when both defects are combined.

The results reported in this paper, together with the reports of Custer and Bok (1975) and ReichD'Almeida and Hockley (1975), strongly suggest that the primary lesion is in the photoreceptor cell (as in 2 above), and that this subsequently inhibits the phagocytic action of the pigment epithelium.
However, the unilateral evidence of these studies has recently been countered by observations on a chimeric rat produced by the aggregation of embryos of albino dystrophic animals with those of pigmented normal animals (Mullen and LaVail, 1976). The resulting animals had mosaic eyes with both pigmented and non-pigmented epithelium. Degeneration of the photoreceptor cells occurred only in patches opposite areas of non-pigmented, dystrophic pigment epithelium, and the authors concluded that the primary lesion was confined to the pigment epithelial cell (as in I above). It is difficult to justify these observations with those of the current paper or previously published reports. However, two further possibilities must be considered. First, it is not known whether the dystrophic cells within the neural retina always come to lie adjacent to dystrophic pigment epithelium. Clearly the initial separation of these two layers and the temporal sequence of invagination and differentiation of the neural retina render this hypothesis unlikely. However, an inductive system may be present, and in the absence of markers for dystrophic photoreceptor cells, it cannot be ignored. Secondly, a primary malfunction in the pigment epithelium which is part of the blood retinal barrier may also give rise to problems in receptor homeostasis which in turn could preclude phagocytosis (as in 3). While the first of these two suggestions is unlikely, the last would explain the anomalies which now exist in the literature.

\section{Summary}

The retinae of I4-day-old Hunter dystrophic rats have been subjected to low-energy irradiation by a pulsed ruby laser. Fifteen days after exposure, pigment epithelial cells had proliferated and repopulated the irradiated areas. In all such areas the subretinal photoreceptor debris had been reduced or lost.

We would like to thank Dr Celia Yates for the donation of a breeding pair of pigmented dystrophic rats and Miss Sally Moore for maintaining the breeding stock. The electron microscope used in this study was a gift from the Wellcome Foundation.

\section{References}

ANSEll, P. L., and MARShall, J. (1974) Exp. Eye Res., 19, 273

BOK, D., and HALL, M. O. (1971) F. Cell Biol., 49, 664

BURDEN, E. M., YATES, c. M., READING, H. W., BITENSky, L., and CHAYEN, J. (1971) Exp. Eye Res., 12, 159

CUSTER, N. V., and BOK, D. (1975) Ibid., 21, I 53

DEWAR, A. J., BARRON, G., and READING, H. W. (1975) Ibid., 20, 63

- - and RICHMOND, J. (1975) Biochem. Soc. Trans., 3, 265

Dowling, J. E., and Sidman, R. L. (1962) $\mathcal{f}$. Cell Biol., 14, 73

FARBER, D. B., and LOLLEY, R. N. (1974) Science, 186, 449 
FEENEY, L., and MIXON, R. N. (1976) Exp. Eye Res., 22, 533

GLOOR, B. P. (1969) v. Graefes Arch. klin. exp. Ophthal., 179, 105

HERRON, W. L., REIGEL, B. W., MYERS, O. E., and RUBIN, M. L. (1969) Invest. Ophthal., 8, 595

HOLLyFIELD, J. G. (1976) Exp. Eye Res., 22, 457

- , and WARD, A. (1974a) $\mathcal{F}$. Ultrastruct. Res., 46, 327

, and - (1974b) Ibid., 46, 339

ISHIKAWA, T., and YAMADA, E. (I970) $\mathcal{F}$. exp. Med., 19, 85

JoHnson, N. F. (1975) Exp. Eye Res., 20, 97

KARNOvSKy, M. L., and WALlaCH, D. F. H. (1963) In 'Rôle du Système Reticuloendothelial dans l' Immunité

Antibactérienne et Antitumorale', ed. B. N. Halpern, p. 147. Centre National de la Recherche Scientifique, Paris KEEFE, J. R. (1973) F. exp. Zoology, 184, 233

lavail, M. M., Sidman, R. L., and o'NeIL, D. (1972) F. Cell Biol., 53, 185

LEURE-DU PREE, A. E. (I97I) PhD thesis, p. 14. University of London

LOLLEY, R. N., and FARBER, D. B. (1976) Exp. Eye Res., 22, 477

MARSHALl, J. (1970a). Vision Res., I0, $82 \mathrm{I}$

- (1970b) Invest. Ophthal., 9, 97

-, and ANSEll, P. L. (1971) F. Anat. (Lond.), I10, 9 I

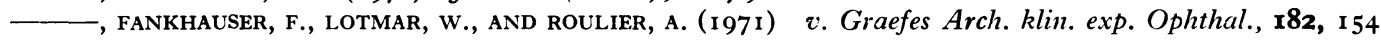

——, and MEllerio, J. (1970) Brit. med. Bull., 26, i 56

meban, c. (1972) f. Anat. (Lond.), 112,195

MULLEN, R. J., and LAVAIL, M. M. (1976) Science, 192, 799

PEDLER, C. M. H., and TILLY, R. (1967) Vision Res., 7, 829

PERKINS, E. S., and BRown, N. A. P. (1973) Brit. F. Ophthal., 57, 487

REICH-D'Almeida, F. B., and hockley, D. J. (1975) Exp. Eye Res., 21, 347

REME, C. E., and YOUNG, R. W. (1976) Ibid., 22, 29

SCHMidT, s. y., and LOLLEy, R. N. (I973) F. Cell. Biol., 57, i I 7

TRIPATHI, R. C., and ASHTON, N. (I976) Application of electron microscopy to the study of ocular inborn errors of metabolism, pp. 69-104 in 'The Eye and Inborn Errors of Metabolism', ed. D. Bergsona, A. Bron, and E. Cotlier. Liss, New York

young, R. W. (1967) f. Cell Biol., 33, $6 \mathrm{I}$

- , and воK, D. (r969) Ibid., 42, 392 